\title{
Influence of Self-Etching Adhesive Systems on Restorative Material Surfaces
}

\author{
${ }^{1}$ Maria Filomena R Lima Huhtala, ${ }^{2}$ Melissa Aline Silva, ${ }^{2}$ Daphne Câmara Barcellos \\ ${ }^{1}$ Carlos Rocha Gomes Torres, ${ }^{1}$ Cesar Rogério Pucci, ${ }^{3}$ Sergio Eduardo de Paiva Goncalves, \\ ${ }^{3}$ Ana Paula Martins Gomes \\ ${ }^{1}$ Assistant Professor, Department of Restorative Dentistry, São José dos Campos School of Dentistry \\ UNESP_São Paulo State University, São Paulo, Brazil \\ ${ }^{2}$ Postgraduate Student, Clinical Research Academic Group, São José dos Campos School of Dentistry \\ UNESP—São Paulo State University, São Paulo, Brazil \\ ${ }^{3}$ Associate Professor, Department of Restorative Dentistry, São José dos Campos School of Dentistry \\ UNESP—São Paulo State University, São Paulo, Brazil
}

Correspondence: Maria Filomena R Lima Huhtala, Avenida Engenheiro Francisco José Longo, 777, Jardim São Dimas, São José dos Campos, São Paulo 12245-000, Brazil, Phone: +55 (12) 3947 9052, Fax: +55 (12) 3947 9010, e-mail: huhtala @ fosjc.unesp.br

\section{ABSTRACT}

This study evaluated the microhardness of restorative materials after the use of self-etching and acid-etching adhesives. Specimens were divided into four groups: Group 1 (CR): Composite resin, Group 2 (GIC): Glass ionomer cement chemically activated, Group 3 (EC): Dual resinous cement, Group $4(E)$ : Dual resinous cement. Each group was divided into three subgroups, according to the type of adhesive system applied on the surface: Subgroup 1 (C): Control subgroup, Subgroup 2 (XE): Xeno III self-etching adhesive, Subgroup 3 (SB): Single bond acid-etching adhesive. Vickers microhardness analysis was performed on the surfaces and the data were submitted to the two-way ANOVA and the Tukey's test. The means for the material factor: GIC: (35.61)a; CR: (43.54)b; E: (44.65)b; EC: (50.13)c. The means for the adhesive factor: SB: (36.35)a; XE: (38.44)a; C: (55.65)b. All materials tested showed a decrease in surface hardness after application of the adhesive systems, irrespective of the system. The lowest microhardness was shown by GIC and the highest by Enforce Core.

Keywords: Acid-etching adhesive systems, Microhardness, Restorative materials, Self-etching adhesive systems.

\section{INTRODUCTION}

A dhesive dentistry began with the development of the acidetching technique by Buonocore ${ }^{1}$ in 1955. This technique provided significant improvements in restorative material retention in prepared cavities, allowing more conservative cavity preparations to be made and reducing marginal microleakage. ${ }^{2} \mathrm{~A}$ dhesive systems began to be the most experimented and studied materials in dentistry, since micromechanical adhesion to the acid-etched enamel surface was shown to be very effective. ${ }^{3}$

Currently, due to marketing appeal, a trend has been observed towards the development of simple systems that associate the simplification of clinical steps and operating time saving. In 1994, Watanabe ${ }^{3}$ et al proposed the use of high concentrations of acidic resinous monomers which, in an aqueous solution, are capable of releasing $\mathrm{H}^{+}$ions and producing etching of the dental structure, at the same time as they penetrate into the substrate. These materials were called self-etching adhesive systems, in which etching of the substratum and its impregnation by resinous monomers occur simultaneously. These adhesive systems involve few operative steps, with the goal of making the adhesive technique faster to save clinical time, and less sensitive, diminishing possible errors, such as bonding imperfections, and extreme acid-etching or drying of dentin. ${ }^{4}$
The self-etching technique dispenses the step of separate application of the acid. The acidity of these adhesive solutions comes from the ionization of radicals present in the molecules of the hydrophilic monomer itself, also responsible for impregnating the substrate. However, several questions have arisen with regards to the performance of these adhesive systems, which have recently come onto the dentistry market, and there is little data with regard to their clinical performance and maintenance of stability. Questions about how their compositions interact with the materials involved in the restoration of teeth have not yet been elucidated.

The concentration of $\mathrm{H}^{+}$ions in the aqueous solution of selfetching adhesive systems and the number of ionized radicals are lower in relation to the concentration of $\mathrm{H}^{+}$ions in the phosphoric acid of total-etch adhesive systems. Phosphoric acid is completely removed from the substrate after performing dental demineralization, while the solutions of self-etching systems are not removed and remain in contact with the dental substrate. $\mathrm{N}$ evertheless, this self-adhesive solution can be completely neutralized by the dissolved minerals in tooth structures, ${ }^{5,6}$ but this cannot occur when such solutions are applied on restorative materials for cavity filling, dentin-pulp complex protection, restorative procedures or cementing prosthetic parts.

The choice of the ideal restorative materials for filling the cavity, protecting the dentin-pulp complex, performing the 
restorative procedure or cementation of prosthetic parts, are aspects of restorative dentistry that continue to raise questions. Currently, with the various types of adhesive systems, retention does not depend only on the physical interaction between restorative material and dental substrate. R etention al so depends on micromechanical bonding of the adhesive systems and the interaction between these systems with the restorative materials and luting agents. ${ }^{7-9}$

Considering the need to verify whether there is interference in the association between restorative materials and adhesive systems, this study was conducted with the objective of evaluating the in vitro action of self-etching and total-etching adhesive systems on the surface microhardness of composite resin, chemically activated glass ionomer cement (GIC) and two dual resinous cements. The null hypothesis was that the adhesive systems do not interfere in the surface microhardness of the materials tested.

\section{MATERIALS AND METHODS}

A prefabricated bipartite Teflon device $2 \mathrm{~mm}$ deep and $5 \mathrm{~mm}$ in diameter was used to make 120 specimens, which were divided into four groups ( $n=30$ ), according to the material used:

\section{Group 1: Composite resin (TPH spectrum)}

Group 2: GIC chemically activated (V idrion R)

Group 3: Dual resinous cement (Enforce Core)

Group 4: Dual resinous cement (Enforce).

The specimens of each material were fabricated according to manufacturers' instructions at controlled temperature of
$23 \pm 2^{\circ} \mathrm{C}$. The materials were included in the matrix in a single increment and a strip of polyester and a glass slide were placed on each material to produce specimens with flat surfaces. For the light polymerized materials, a halogen light device with an intensity of $500 \mathrm{~mW} / \mathrm{cm}^{2}$ (Curing Light XL 3000, 3M Dental Products, St. Paul, MN) was used, with the tip of the light polymerizer unit placed directly onto the polyester strip. For the GIC, the amount of powder necessary to prepare each specimen was weighed in an electronic analytical balance (AS 310; Scientech Inc., B oulder, CO, USA ) and mixed to the liquid with a spatula onto an impermeable mixing pad. For all groups, 10 minutes after the inclusion the samples were gently removed from the matrix.

Next, each group was sub-divided into three subgroups ( $n=10$ ), distributed according to the type of adhesive system applied on the surface:

\section{Subgroup 1 (SG1): Control subgroup}

Subgroup2 (SG2): X eno III self-etching adhesivesystem (Dentsply)

Subgroup 3(SG3): A dper Single B ond 2 acid-etching adhesive system (3M ESPE).

The technical data of materials used are listed in Table 1.

The subgroup 1 (control subgroup), no type of adhesive system was used. Subgroup 2 received one layer of self-etching adhesive system X eno III (Dentsply) used in a single step according to the manufacturer's recommendations: M ix of liquids $A$ and $B$, application and the waiting time of 20 seconds followed by light polymerization for 10 seconds. For subgroup 3 , the surface received two layers of the acid-etching adhesive A dper Single Bond (3M ESPE) used in accordance with the

Table 1: Products, manufacturers and compositions

\begin{tabular}{|c|c|c|}
\hline Material & Manufacturer & Composition \\
\hline TPH spectrum & $\begin{array}{l}\text { Dentsply De Trey } \\
\text { GmbH D, Konstanz, Germany }\end{array}$ & $\begin{array}{l}\text { Bis-GMA (Bisphenol-A-glycidil-methacrylate), } \\
\text { UDMA (urethane dimethacrylate), barium silicate }\end{array}$ \\
\hline Vidrion $\mathrm{R}$ & SS White, Rio de Janeiro, RJ, Brazil & $\begin{array}{l}\text { Sodium fluorsilicate, calcium aluminum, barium sulfate, } \\
\text { polyacrylic acid, pigments }\end{array}$ \\
\hline Enforce & $\begin{array}{l}\text { Dentsply De Trey } \\
\text { GmbH D, Konstanz } \\
\text { Germany }\end{array}$ & $\begin{array}{l}\text { Bis-GMA, BHT (2,6 Di-tert-butyl-4-methylphenol), } \\
\text { EDAB (4-ethyl diaminobenzoato), BDMA (bisphenol A } \\
\text { dimethacrylate ethoxylate), HEMA (2-hydroxyethyl } \\
\text { methacrylate), TEGMA (triethyleneglycol } \\
\text { dimethacrylate), fumed silica, silanized barium, alumina } \\
\text { borum-silicate glass ( } 66 \text { wt } \% \text { ). }\end{array}$ \\
\hline \multirow[t]{2}{*}{ Enforce core } & $\begin{array}{l}\text { Dentsply De Trey } \\
\text { GmbH D, Konstanz, Germany }\end{array}$ & $\begin{array}{l}\text { Urethane-modified Bis-GMA, inorganic fluoride, } \\
\text { pigments, benzoate peroxide, photoinitiators, } \\
\text { stabilizers }\end{array}$ \\
\hline & & $\begin{array}{l}\text { Liquid A: HEMA ( } 2 \text {-hydroxyethyl methacrylate), ethanol, } \\
\text { amorphous silicon purified, water, Toluene } \\
\text { hydroxybutyrate (THB) }\end{array}$ \\
\hline Xeno III & $\begin{array}{l}\text { Dentsply De Trey } \\
\text { GmbH D, Konstanz, Germany }\end{array}$ & $\begin{array}{l}\text { Liquid B: Piro-EMA (methyl functionalized with } \\
\text { phosphoric acid), EMP-F (monofluoride phosphazene } \\
\text { modified), UDMA of THB, camphorquinone } \\
\text { ethyl-4-dimethylamino-benzoate }\end{array}$ \\
\hline Adper single bond 2 & 3M ESPE/St Paul, MN, USA & $\begin{array}{l}\text { Water, alcohol, HEMA, Bis-GMA, dimethacrylate, } \\
\text { photoinitiator, copolymers of the acid and poly (itaconic) } \\
\text { acid }\end{array}$ \\
\hline
\end{tabular}


Influence of Self-Etching Adhesive Systems on Restorative Material Surfaces

manufacturer's indication. The excess of bond was removed with jet of air for 2 seconds and light polymerized for 10 seconds.

The 120 specimens were stored at $37{ }^{\circ} \mathrm{C}$ for 30 days, in dark flask to prevent the passage of light, and an $85 \%$ relative humi dity environment. ${ }^{10} \mathrm{~N}$ ext, the analysis was performed using the Vickers M icrohardness Digital (FutureTech FM-700, Tokyo, Japan) appliance, with a $50 \mathrm{gm}$ load and dwell time of 15 seconds. The specimen surfaces were subjected to three readings, respectively, to cal culate a mean value.

The data were submitted to two-w ay A NOV A, these being material and adhesive, followed by the Tukey's test. The level of significance adopted was $5 \%$.

\section{RESULTS}

The result of the two-way ANOVA is shown in Table 2. For the factor material, significant differences were obtained as $p<0.05$. For the factor adhesive, significant differences were observed to be $p<0.05$. For the interaction between material

\begin{tabular}{lcrc}
\multicolumn{4}{c}{ Table 2: Results for two-way ANOVA } \\
\hline Factor & Degree of freedom & $F$ & $p$ \\
\hline Material & 3 & 23.05067 & $0.05^{*}$ \\
Adhesive & 2 & 73.56496 & $0.05^{*}$ \\
Material $\times$ adhesive & 6 & 8.77702 & $0.05^{*}$
\end{tabular}

*Significant differences

Table 3: The mean values and the results of Tukey's test for the factor adhesive

\begin{tabular}{|c|c|c|}
\hline Adhesive & Mean & Homogeneous sets* \\
\hline Single bond & 36.35 & $A$ \\
\hline Xeno III & 38.44 & $A$ \\
\hline Control & 55.65 & B \\
\hline
\end{tabular}

*Means accompanied by the same letters presented no statistically significant differences
Table 4: The mean values and the results of Tukey's test for the factor material

\begin{tabular}{|c|c|c|}
\hline Material & Mean & Homogeneous sets* \\
\hline Vidrion $\mathrm{R}$ & 35.61 & $A$ \\
\hline TPH spectrum & 43.54 & $B$ \\
\hline Enforce & 44.65 & $B$ \\
\hline Enforce core & 50.13 & $\mathrm{C}$ \\
\hline
\end{tabular}

*Means accompanied by the same letters presented no statistically significant differences

and adhesive factors, significant differences were obtained as $p<0.05$.

The microhardness means and results of the Tukey's test for the factors adhesive and material are shown in Tables 3 and 4. A s regards the adhesive factor, the control group showed a significantly higher mean microhardness than the other groups that implemented the acid-etching adhesive system Single B ond, and adhesive and self-etching adhesive system X eno III. W ith regard to the material factor, the GIC (V idrion $\mathrm{R}$ ) showed the lowest microhardness values, differing statistically from all the tested materials. The dual resinous cement (Enforce Core) showed the highest microhardness values, differing statistically from all the tested materials.

In Table 5, Tukey's tests were applied for the interaction between the factors material and adhesive. The GIC (V idrion R) treated with acid-etching adhesive system Single B ond showed the lowest microhardness values and the dual resinous cement (Enforce Core) that did not receive any treatment with adhesive system exhibited the highest microhardness values.

\section{DISCUSSION}

The development of the restorative materials in esthetic restorations in which the professional uses for the bonding of inlays, crowns, posts, bridges and orthodontic bands on or in the tooth and as cavity linings, bases or filling materials began a revolution in many areas of restorative dentistry. Restorative material retention in prepared cavities depends on the physical

\begin{tabular}{|c|c|c|c|c|c|c|c|c|}
\hline Material & Adhesive & Mean & Ho & leo & $t s^{*}$ & & & \\
\hline Vidrion R & Single bond & 32.30 & $A$ & & & & & \\
\hline Vidrion $\mathrm{R}$ & Xeno III & 32.77 & $A$ & B & & & & \\
\hline Enforce core & Single bond & 34.51 & $A$ & B & & & & \\
\hline Enforce & Xeno III & 36.57 & $A$ & B & C & & & \\
\hline Enforce & Single bond & 37.85 & $A$ & B & C & & & \\
\hline TPH spectrum & Xeno III & 40.06 & $A$ & B & $\mathrm{C}$ & $\mathrm{D}$ & & \\
\hline TPH spectrum & Single bond & 40.75 & $A$ & B & $\mathrm{C}$ & $\mathrm{D}$ & & \\
\hline Vidrion $\mathrm{R}$ & Control & 41.76 & & B & $\mathrm{C}$ & D & & \\
\hline Enforce core & Xeno III & 44.37 & & & C & $\mathrm{D}$ & & \\
\hline TPH spectrum & Control & 49.82 & & & & $\mathrm{D}$ & $E$ & \\
\hline Enforce & Control & 59.52 & & & & & $E$ & $\mathrm{~F}$ \\
\hline Enforce core & Control & 71.52 & & & & & & $\mathrm{~F}$ \\
\hline
\end{tabular}

*Means accompanied by the same letters presented no statistically significant differences 
interaction between restorative material and dental substrate (micro-mechanical and chemical bonding). However, the chemical interaction between the adhesive systems and these restorative materials can adversely alter the physical properties. This study investigated a simple, but important question relative to the use of the total-etch and self-etching adhesive systems on the surface microhardness of composite resin, chemically activated glass ionomer cement and two dual resinous cements.

The null hypothesis was rejected because the adhesive systems interfered in the surface microhardness of all the tested materials. With regard to the adhesive factor, this study showed that the self-etching adhesive system X eno III and the totaletch adhesive system Single Bond promoted lower microhardness values that were statistically significant when compared with the control subgroup.

The polymerization reaction of the light-curing of resinbased restorative materials goes on for a certain time after photoactivation. The hardness and the stress resistance of the lightcuring of resin-based restorative materials are directly associated to resinous monomers conversion into polymers. Consequently, the application of the adhesive systems immediately after light curing may undermine the mechanical properties of the restorative materials because after photoactivation, the resin exhibits great difference in microhardness values between the organic and inorganic components. ${ }^{2}$

A disadvantage of 'one step' self-etching adhesives is seen in their relatively high water uptake. ${ }^{11,12}$ To the self-etching adhesive systems that involve two components and an application of one step, polar and apolar ingredients of the solution are blended together with a solvent, such as water, acetone or ethanol..$^{13}$ The self-etching $X$ eno III presented water and alcohol in the composition. The water component can prevent the formation of coval ent $C=C$ bonds, which may have compromised the post-polymerization of restorative materials, ${ }^{8,14}$ and lowered the surface microhardness in comparison with the control subgroup. The alcohol component can act as resin solvent, ${ }^{7}$ softening the composite and releasing powder particles on its surface, ${ }^{14,15}$ which may have affected the surface microhardness of the restorative materials when compared with the control subgroup. M oreover, variations in microhardness were not dependent on the adhesive system used.

A dditionally, the manufacturer of the X eno III stated that its self-etching systems showed high etching efficacy with a $\mathrm{pH}$ value of less than 1 (esters of phosphoric acid - Piro-EM A) and the neutralization of acidic components occurs by dissolving calcium hydroxyapatite on the tooth surface. ${ }^{5,11}$ This result may be due to the absence of cal cium hydroxyapatite on the material surface to neutralize the acidic components of the self-etching adhesives systems, that can reduce the surface hardness of the materials tested in comparison with the control subgroup that did not use any type of adhesive system.

On the other hand, when a water-containing, ethanol-based adhesive system, such as Single B ond is used, the residual water remaining after ethanol solvent evaporation may interfere with the surface hardness of the materials tested in comparison with the control subgroup. A dditionally, Single B ond has $\mathrm{pH}$ value 3.6, which is possibly related to the presence of acidic monomers in their compositions. ${ }^{14}$ This result may be due the absence of calcium hydroxyapatite on the material surface to neutralize the acidic components of the self-etching and total-etching adhesives systems. ${ }^{5,6}$

For the material factor, this study showed the lowest surface microhardness values for the glass ionomer (V idrion R). GICS are still considered the only materials that self-adhere to tooth tissue. ${ }^{3}$ Chemical bonding is obtained by ionic interaction of the carboxyl groups of the polyal kenoic acid with calcium ions of hydroxyapatite that remained attached to the collagen fibrils. ${ }^{16} \mathrm{GIC}$ are usually hydrolytically unstable at initial stages of setting (gelation) when exposed to air. If exposed to moisture, GICs can uptake water while essential ions can be lost. W orsening of the mechanical properties can be a consequence of both processes: water loss and/or uptake in early stages of the setting reaction. ${ }^{2}$

V idrion R showed lower microhardness that was statistically significant in comparison with all the tested materials. Because conventional glass ionomer cements are moisture sensitive, a surface coating is recommended during the initial setting stage. Several authors ${ }^{7,17-24}$ recommend the use of protective agents on the material surface, such as adhesive systems, vaseline and nail varnish, for materials that can be varnished.

However, the results of this study showed that the application of total-etching adhesive system Single B ond decreased the surface microhardness of the Vidrion R. This result can be explained by the findings of the Serra ${ }^{18}$ et al who claim that the photoactivated adhesive systems do not provide satisfactory protection on the cement surface, probably due to the high angle of contact formed between the adhesive and cement, which could have harmed the bond of these two materials. Therefore, the use of varnishes ${ }^{21}$ and nail varnish ${ }^{20}$ is more effective and protective against the water solubility of the glass ionomer restorative cements when compared with glaze-resin.

However, some authors recommend the use of total-etching adhesive system to protect GICs. Haddad et $a^{23}$ (1992) compared the efficiency of protective seal ants for glass ionomer cements using liquid scintillation spectrometry. They concluded that the resin component of Scotchbond 2 was a very effective sealant for the newly placed glass ionomer cement, however, when mixing the two components of the Scotchbond 2 adhesive system, results in porosity in the surface of the GIC which allowed the passage of water in the initial stages of setting (gelation) of the material. Watson and Banerjee ${ }^{24}$ evaluated the efficacy of three surface protection treatments (copal varnish, unfilled bonding resin and a dentine bonding agent) in preventing water penetration into glass-ionomer cements using confocal light microscopy. They concluded that the dentine 
Influence of Self-Etching Adhesive Systems on Restorative Material Surfaces

bonding agent was able to remain adhered to the GIC underlying probably due to its hydrophilic property, forming a continuous barrier to the penetration of water.

For the adhesive factor, it was noted that the composite resin (TPH spectrum) and the dual resinous cement Enforce demonstrated lower values that were statistically significant in comparison with the dual resinous cement Enforce Core. However, on analysis of the interaction between the factors (see Table 5) for the Enforce and Enforce Core, it was noted that the control subgroup showed higher microhardness that was statistically significant in comparison with the subgroups that used adhesive systems. Initial activation of the dual resinous cement (Enforce Core and Enforce) occurs by means of light polymerization and is finalized by chemical polymerization. There was evidence to suggest that the composite resin cements were influenced by the compatibility of polymerization modes between adhesives systems and resin composites. ${ }^{12} Y$ amauchi ${ }^{16}$ and Sanares et al ${ }^{14}$ speculated an incompatibility of adhesive systems containing acidic resin monomers with chemical cured resins or dual curing resin cements.

A ccording to Sanares et al, ${ }^{14}$ when single-bottle adhesives are used together with chemical-cured composites, there is an interaction of the residual acidic resin monomers from the adhesive inhibition layer with the binary peroxide-amine catalytic components that is commonly employed in chemically cured resin composites. The acidic resin monomers polymerized poorly in the presence of peroxide-amine redox systems, as the tertiary amines were neutralized by the acidic resin monomers and lost their ability as reducing agents in redox reactions. ${ }^{14,16}$ Reactions products may be deposited as globular structures within some of the voids found al ong the composite-adhesive interfaces. Thus, the dilution of the free radical concentration will result in slow or no polymerization, depending upon the acidity and concentration of the acidic resin monomers. A dequate polymerization is a crucial factor in obtaining optimal mechanical properties to improve the clinical performance of resin composite materials. The hardness and the stress resistance of the composite are directly associated to conversion monomers resinous into polymers.

On analysis of the interaction between the factors (Table 5), it was observed that TPH spectrum with the adhesive systems Single B ond and $X$ eno III showed no statistically significant differences when compared with the control subgroup. Lightcured systems utilize photochemical redox systems that also involve the use of tertiary amines. ${ }^{14}$ However, the ratio of initiation of free radicals in light-cured systems is much faster than chemical-cured systems. Thus, this study demonstrates that the light-cured composite do not have alterations on surface microhardness when utilized adhesive systems.

The surface hardness can have a negative correlation with the erosion of material, when subjected to chewing loads. ${ }^{25,26}$ The results of this study indicate that the self-etching and conventional acid-etching adhesive systems promoted changes in surface microhardness of the restorative materials, but they behaved in the same way for the conventional acid-etching adhesive, which also showed variation in microhardness in comparison with the control subgroup. It will be of clinical significance to further investigation how these adhesive systems will affect to surface hardness of the restorative materials.

\section{CONCLUSION}

The self-etching adhesive $X$ eno III behaved in the same way for the conventional acid-etching adhesive systems. However, all adhesive systems tested showed decrease in hardness after the application in surface of the GIC (Vidrion R) and dual resinous cements (Enforce and Enforce Core) restorative materials, except to the light-cured composite resin.

\section{REFERENCES}

1. B uonocore M G. A simple method of increasing the adhesion of acrylic filling materials to enamel surfaces. J Dent Res 1955;34:849-53.

2. A nusavice KJ. Phillips materials dentários. Rio de Janeiro: Guanabara K oogan 1998.

3. Watanabe I, Nakabayashi N, Pashley DH. B onding to ground dentin by Phenil-P self-etching primer. J Dent Res 1994; 1212-20.

4. B rackett WW, Tay FR, L ooney SW, Ito S, Haisch L D, Pashley $\mathrm{DH}$. M icrotensile dentin and enamel bond strengths of recent self-etching resins. Oper Dent 2008;33:89-95.

5. Finger WJ, Fritz $U$. Laboratory evaluation of one-component enamel/dentin bonding agents. A m J Dent 1996;9:206-10.

6. Kim JH, Lee YK, Powers J M. Influence of a series of organic and chemical substances on the translucency of resin composites. J Biomed M ater Res B A ppl Biomater 2006;77:21-27.

7. M iyazaki $M, H$ inoura $K$, Honjo $G$, Onose $H$. Effect of selfetching primer application method on enamel bond stength. A m J Dent 2002;15:412-16.

8. Nakabayashi N, Takarada K. Effect of HEMA on bonding to dentin. Dent M ater 1992;8:125-30.

9. Tay FR, Pashley DH, Garcia-Godoy F, Y iu CK. Single-step, self-etch adhesives behave as permeable membranes after polymerization (Part II). Silver tracer penetration evidence. A m J Dent 2004;17:315-22.

10. A smussen E. Composite restorative resins. Composition versus wall-to-wall polymerization contraction. A cta Odont Scand 1975;33:337-44.

11. Sneed WD, Draughn RA. Effect of alcohol on the strength of composite resin. Oper Dent 1980;5:47-48.

12. Swift EJ J r, M ay K N J r, Wilder A D J r. Effect of polymerization mode on bond strengths of resin adhesive/cement systems. J Prosthodont 1998; 7:256-60.

13. V an Landuyt $K L$, Snauwaert J, Peumans M, De M unck J, $L$ ambrechts $P, V$ an $M$ eerbeek $B$. The role of HEM A in onestep self-etch adhesives. Dent M ater 2008;24:1412-19.

14. Sanares AM, Itthagarun A, King NM, Tay FR, Pashley DH. A dverse surface interactions between one-bottle light-cured adhesives and chemical-cured composites. Dent M ater 2001;17:542-56.

15. Dulik D, B ernier R, B rauer GM . Effect of diluent monomer on the physical properties of bis-GMA-based composites. J Dent Res 1981;60:983-89.

16. Y amauchi J. Study of dental adhesive containing phosphoric acid methacrylate monomer. Jap J D ent M ater 1986;5:144-54. 
17. Philips S, B ishop BM . A n in vitro study of the effect of moisture on glass-ionomer cement. Q uintessence Int 1985;16:175-77.

18. Serra M C, N avarro M FL, F reitas SFT, Carval ho RM , C ury JA, Retief $\mathrm{H}$. Glass ionomer cement surface protection. A m J Dent 1994:7:203-06.

19. Y oshida $Y$, V an M eerbeek B, Nakayama Y, Snauwaert J, Hellemans $L$, $L$ ambrechts $P$, et al . Evidence of chemical bonding at biomaterial-hard tissue interfaces. J Dent Res 2000;79: 709-14.

20. Hotta M, Hirukawa H, Y amamoto K. Effect of coating materials on restorative glass-ionomer cement surface. Oper Dent 1992;17:57-61.

21. Rodrigues Garcia RC, De Góes M F, Del B el Cury A A . Influence of protecting agents on the solubility of glass ionomers. A m J Dent 1995;8:294-96.
22. Valera VC, Navarro M FL, Taga EM, Pascotto RC. Effect of nail varnishes and petroleum jelly combinations on glass ionomer dye uptake. A m J Dent 1997;10:251-53.

23. Haddad D, M ount GJ, M akinson OF. Efficiency of protective sealants for glass ionomer cements. A m J Dent 1992;5:286-88.

24. Watson $T, B$ anerjee $A$. Effectiveness of glass ionomer surface protection treatments: A scanning optical microscope study. Eur J Prosthodont Rest D ent 1993;2:85-90.

25. De Gee A J, V an Duinen RN B, W erner A, Davidson CL. Early and long-term wear of conventional and resin-modified glass ionomers. J Dent Res 1996;75:1613-19.

26. De M oor RJ G, V erbeeck RM H. Changes in surface hardness of conventional restorative glass ionomer cements. Biomaterials 1998;19:2269-75 